\title{
A measuring method based on photodiodes for the diagnostic of optimal combustion conditions
}

\author{
L. Arias ${ }^{1}$, O. Farías ${ }^{2}$, S. Torres ${ }^{1} \&$ D. Sbárbaro ${ }^{1}$ \\ ${ }^{I}$ Department of Electrical Engineering, University of Concepción, Chile \\ ${ }^{2}$ Department of Mechanical Engineering, University of Concepción, \\ Chile
}

\begin{abstract}
A non-intrusive method for monitoring flames in gas burners is presented. The method is based on the optical analysis of the flame by using a Silicon Photodiodes array and a set of interference optical filters. The covered wavelengths evaluate the formation and behaviour of excited $\mathrm{CH}^{*}$ and $\mathrm{C}_{2}{ }^{*}$ radicals for confined gas flames. The monitoring of these radicals is carried out in the flame reaction region at the burner exit, where the $\mathrm{C}_{2} * / \mathrm{CH}^{*}$ ratio signals provide enough information to identify the optimal fuel-air ratio in order to obtain the boiler maximal efficiency and to prevent an incomplete combustion. The experimental results obtained for two power levels, in a boiler of $150 \mathrm{~kW}$, demonstrate that the $\mathrm{C}_{2} * / \mathrm{CH}^{*}$ ratio provides important information concerning the combustion state and gives a clear indication about the burner adjustment when $\mathrm{CO}$ emissions begin to increase to the upper the levels accepted by environmental laws. The fast response and its non-intrusive character give to the proposed optical sensor an important potential to be used in advanced control strategies for the on-line optimization of the combustion process.

Keywords: combustion, gas, flame spectrum, photodiodes, optimization, optical sensor.
\end{abstract}

\section{Introduction}

The monitoring of the combustion state in boilers and industrial furnaces is limited due to the hostile environment. Indeed, the high temperature, the corrosive atmosphere and the limited access to the flame characteristics restrict a reliable diagnostic. The information provided by conventional combustion 
instruments is clearly insufficient to act on the burner settings, which would be an effective way to optimize the flame, to operate at high thermal efficiency, reducing emissions of carbon monoxide and/or nitrogen oxides. Thus, the development of wireless sensors with a non-intrusive character is highly important.

The application of control techniques for combustions systems is of great interest. However, reliable combustion control techniques need reliable sensors and this depends on the characteristics of the combustion process. In this case, many groups of sensors has been analysed and applied at an industrial level $[1,5]$. For gas sensing, the following classes of sensors have been revised:

- Solid electrolyte $\mathrm{ZrO}_{2}$ sensors for $\mathrm{O}_{2}$ and $\mathrm{CO}$.

- Solid electrolyte, non-nernstian $\mathrm{ZrO}_{2}$ sensor for $\mathrm{CO} / \mathrm{H}_{2}$.

- Thin-film semi-conductor sensors $\left(\mathrm{SnO}_{2}, \mathrm{Ga}_{2} \mathrm{O}_{3}, \mathrm{Nb}_{2} \mathrm{O}_{5}\right)$ for oxidising or reducing gases.

- Thermal conductivity sensor for $\mathrm{CO}_{2}$.

- Sensors and optical methods using radiative properties of flames: spectrometry, spatio-temporal signature.

- The potential of some generic technologies being developed, in particular those using laser diodes and those using diamond coatings.

- Optical methods using the flame signature principle.

The optical methods, used in the characterization of combustion quality and pollutant emissions by means of the flame signature principle, have been studied and developed in many works. However, their application at an industrial level is difficult today [1,5].

In particular, the massive use of radiometric techniques $[3,4,7,10,11,22]$ has contributed to a better understanding of the combustion processes. It is known that in the reaction zone of hydrocarbon flames, the oxygen of the air reacts with the fuel to liberate the chemical energy stored in the molecular bond. This energy is reflected in the visible flame spectrum around certain narrow wavelengths and a continuous background. The discontinuous spectra of atoms or molecules are arranged in groups, each group being called a band of free radicals [2]. A typical case of gas flames burned by diffusion into the surrounding air show yellow luminosity due to the formation of soot. Soot emissions are similar to that of a grey body but with a more complex variation of emissivity with the wavelength $[3,12]$. In gas premixed flames, a CO continuum has been identified in the range of wavelength from $300-550 \mathrm{~nm}$ [3].

The radical's intensities detection has been greatly used to obtain the combustion state index. The radicals better detected are those found in the short wavelength, because of having a lower interference with the emission of soot particles. In this case, $\mathrm{CH}^{*}$ (at $432 \mathrm{~nm}$ ) and $\mathrm{C}_{2} *$ (at $516 \mathrm{~nm}$ ) radicals are very interesting because they provide easily observable signals, with a strong intensity, and their radiation is spectrally resolved. $\mathrm{OH}^{*}$ radical $(306-315 \mathrm{~nm})$ is attractive because of the reduced background emission at this wavelength. On the other hand, the $\mathrm{CH}^{*}$ radical has been identified as the best marked on the flame front and it is often used as a measure of the heat release rate. In many works, the intensity emissions and the ratio of different radicals have been used in order to 
identify clearly the main flame zones, air-fuel ratio, and pollutant emissions amongst others. Thus, the ratios $\mathrm{CH}^{*} / \mathrm{OH}^{*}, \mathrm{C}_{2} * / \mathrm{OH}^{*}$ and $\mathrm{C}_{2} * / \mathrm{CH}^{*}$ show a nearly linear function of equivalence ratio $[19,22]$. Also, the correlation between chemiluniscence of any radicals and the flame temperature has been investigated [22].

The study and application of sensitive photodiodes in the UV-VI range, for spectral emission detection, was carried out in the last 10 years. However, the polarisation mode of these photodetectors is not mentioned. Khesin $[14,15]$ applied photodetectors to realize combustion control in pulverized coal burners at an industrial level, by measurement of the flame instability. In recent years a method based on a Si photodiode (with spectral response 190-1100nm) has been used $[17,18]$. The signal of this sensor integrates the contribution of different excited radicals and continuous spectra and uses the rms average of the 'flame luminosity', which is compared with the CO emissions. Also, a Photomultiplier has been used with an optical filter in $310 \pm 10 \mathrm{~nm}$ to detect the $\mathrm{OH}^{*}$ radical intensity. Another method is based on the utilization of UV cells [16], which is based on Si (UV enhanced) and GaP junctions and the signal generated by the photodetectors is acquired and post-processed. The light is collected by means of a lens and optical fibre and the detector cell is installed in a tube, inside the burner. A correlation has been obtained between $\mathrm{O}_{2}$ emissions and the flame stability, but this correlation changes for different boiler geometry, burner/boiler types and load.

Additionally, others techniques have been used by means of the flame spectrum. For example, the flame temperature has been estimated by using the two or more wavelengths methods, through the spectral emission measurement of soot particles $[2,3,9,11]$. Moreover, the gas emission has been estimated through absorption spectroscopy by using laser diodes $[1,5,6]$. On the other hand, different camera technologies have been used to define combustion parameters from the flame morphology [19,21].

The flame spectrum intensity depends on many variables such as the temperature, the kind of gas mixture, fuel-air ratio, the burner type, the turbulence, and the flame area observed. Therefore, the main purpose of this investigation is to characterize the influence of the combustion parameters by use of a photodiode array in order to propose an optimal combustion control system. Thus, an optical method for monitoring flames in gas burners is developed. Further, the optical analysis of the flame is achieved by using a Silicon Photodiodes array and a set of interference optical filters. The optical sensor is able to measure the $\mathrm{C}_{2}{ }^{*}$ and $\mathrm{CH}^{*}$ signals, and the ratio of these radicals provides enough information to identify the optimal fuel-air ratio in order to obtain the boiler maximal efficiency and to prevent an incomplete combustion.

\section{Monitoring a gas flame by using photodiodes}

The objective of this paper is to describe the advantage of the photodiodes utilization in order to determinate the combustion state and use this information for a combustion control strategy. 
In this paper, a new monitoring method for $\mathrm{CH}^{*}$ and $\mathrm{C}_{2} *$ radicals, by using silicon photodiodes equipped with optical filters centered in the corresponding emissions bands is presented.

The spectral responsivity of these devices is between $380-1200 \mathrm{~nm}$, with a maximal response at $850 \mathrm{~nm}$. The center wavelength of filters for detection of $\mathrm{CH}^{*}$ emissions is $430 \pm 5 \mathrm{~nm}$ and $514.5 \pm 5 \mathrm{~nm}$ for $\mathrm{C}_{2} *$ emissions, with a transmission of $45 \%$ and $70 \%$, respectively. The difference between the filter transmission and responsivity intensity was corrected by software. The polarization mode for driving the photodiodes signals was the Photoconductive. Thus, a linear response is obtained by using this mode between the photon incidence and the current generated.

The flame area covered by the photodiodes is observed from the exit burner. The specific installation of these devices is shown in figure 1, where the photodiode array is cooled by means of fresh gas and air flux and the distance between the photodiodes and the flame basis is $8 \mathrm{~cm}$. The reaction zone is observed, with a FOV of $72^{\circ}$, where the formation of these radicals is strong $[3,22]$. The experimental results were performed in a central heating boiler of $150 \mathrm{~kW}$, equipped with a Riello GS20 gas burner. The test bench was instrumented with gas and water flow meters, thermocouples and gas analyser (at the exit of the chimney) in order to obtain the on-line parameters of combustion and boiler efficiency. The photodiodes driver's signals were recorded in the computer by using a DAQ board at $100 \mathrm{kHz}$, and processed by the LabView interface. The tests reported in this paper were performed covering two firing rate values: 150 and $130 \mathrm{~kW}$.

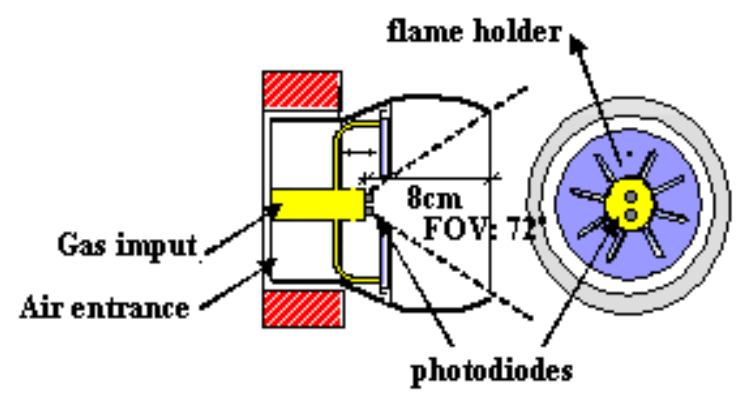

Figure 1: Photodiodes installation.

\section{Experimental results}

Figure 2 show the spectral intensity of the gas flame, obtained from the burner exit by using the USB2000 Radiometers operating in the visible range. It is possible to distinguish clearly the main bands of $\mathrm{CH}^{*}$ and $\mathrm{C}_{2}{ }^{*}$ radicals. One verifies that the main reacting zone may be characterised by these specific emissions and provides more observable signals to be monitored by the photodiode array. 


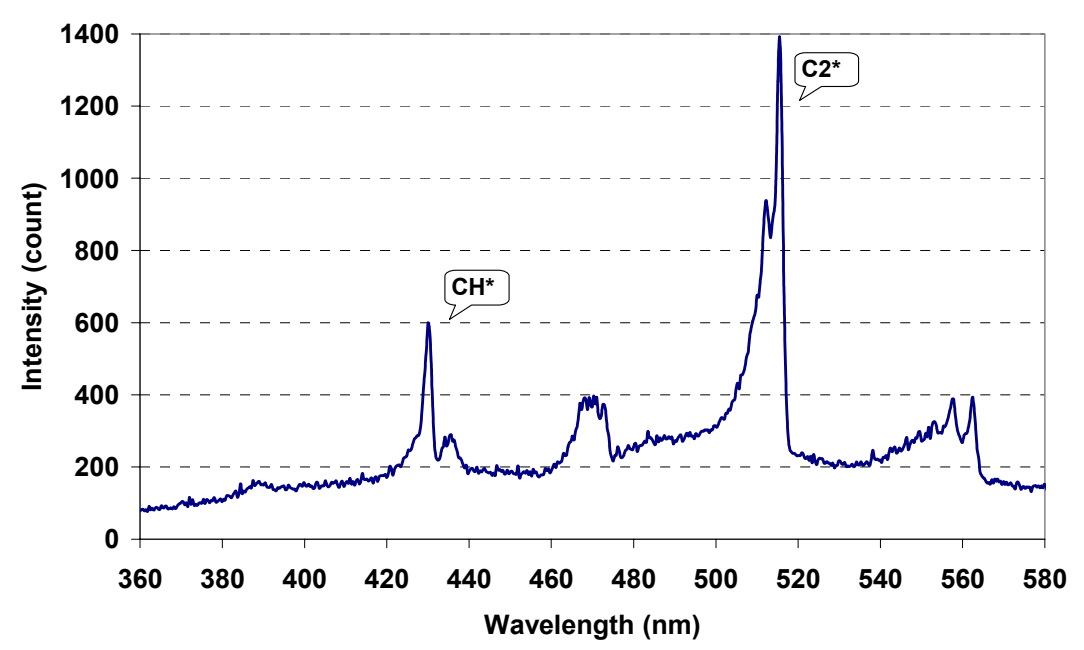

Figure 2: $\quad \mathrm{C}_{2} *$ and $\mathrm{CH}^{*}$ radicals at the reaction zone.

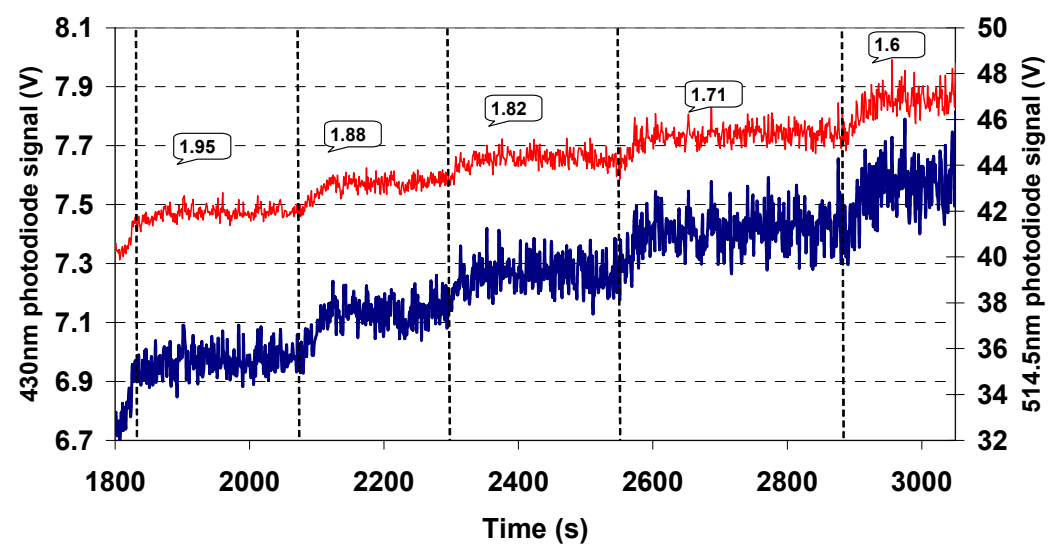

$-430 \mathrm{~nm}-514.5 \mathrm{~nm}$

Figure 3: $\quad$ On-line response, photodiodes at 430 and $514.5 \mathrm{~nm}$.

In the tests performed, the air flow was decreased by closing the burner air damper and the real time response of the photodiodes and gas analyzers were registered. Figure 3 shows the online response of the photodiodes, for different air excesses $($ Lambda $=1+e)$, where it's possible to observe that the change in the air flow is followed by the array sensor. Also, as in figure 2, the $\mathrm{C}_{2} *$ radical intensity is stronger than the $\mathrm{CH}^{*}$ radical. The great difference between the 


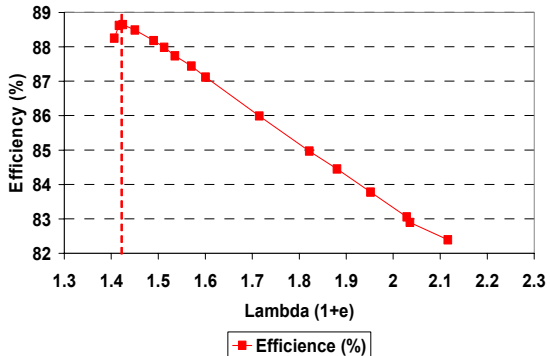

(a)

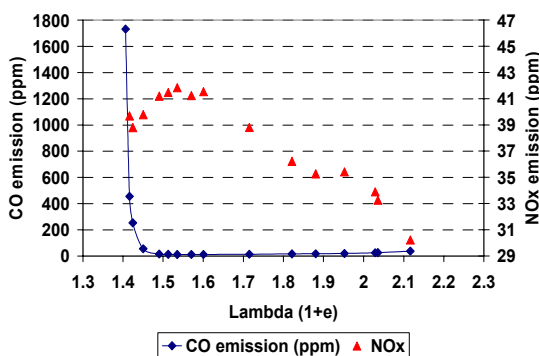

(c)

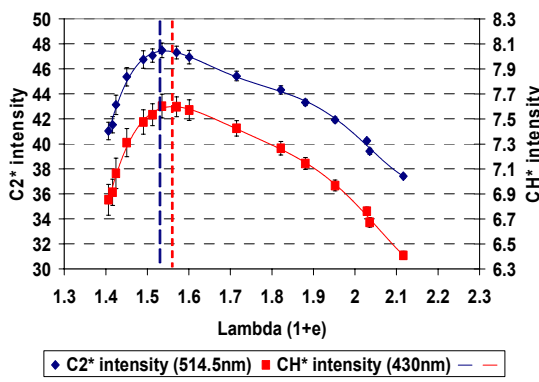

(e)

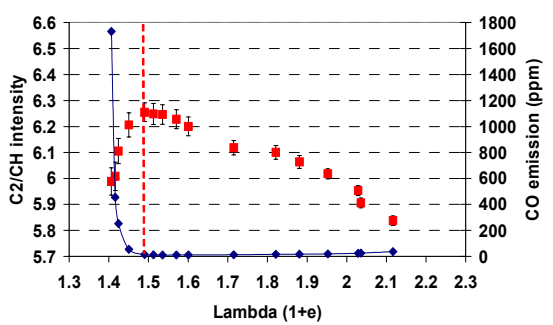

$\square \mathrm{C2} / \mathrm{CH}$ intensity $\rightarrow$ CO emission (ppm)

(g)

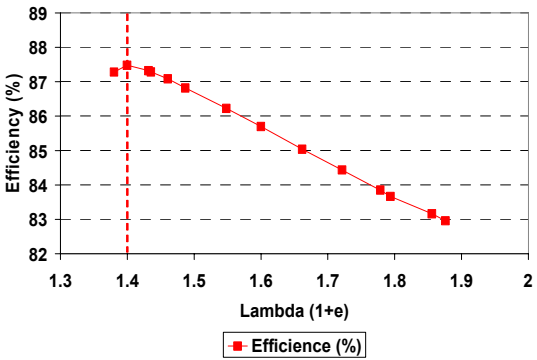

(b)

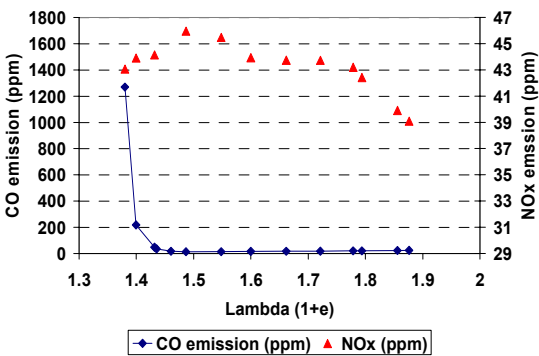

(d)

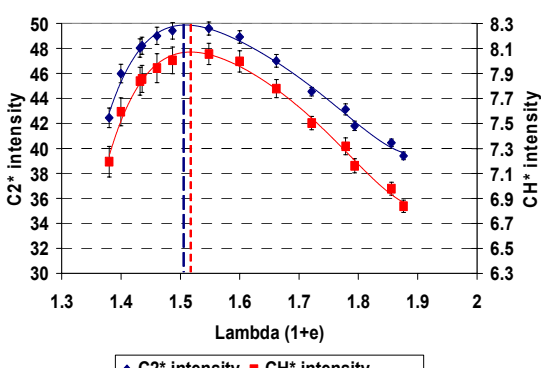

(f)

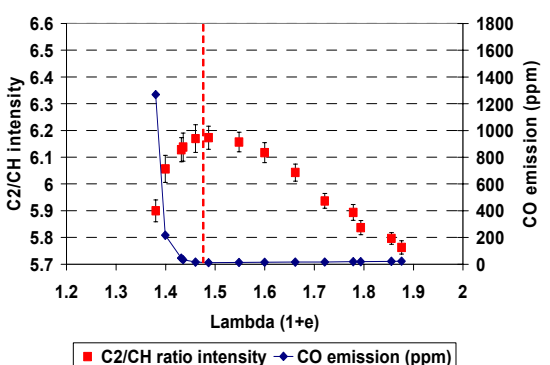

(h)

Figure 4: Test boiler resume for two power levels: $130 \mathrm{~kW}$ (in left column) and $150 \mathrm{~kW}$ (in right column) for change in the air excess. $(\mathrm{a}, \mathrm{b})$ Thermal efficiency $(\mathrm{c}, \mathrm{d}) \mathrm{CO}$ and NOx emissions. (e,f) Absolute intensity of $\mathrm{CH}^{*}$ and $\mathrm{C}_{2} *$ radicals detected by the photodiodes array. $(\mathrm{g}, \mathrm{h}) \mathrm{C}_{2} * / \mathrm{CH}^{*}$ intensity ratio. 
intensity of these signals is because the filters have a FWHM (full width at half maximum) of $10 \mathrm{~nm}$. In this case, the integrated signal from the photodiode at $514.5 \mathrm{~nm}$ is bigger than photodiode at $430 \mathrm{~nm}$

Figure 4 shows the results of the boiler performance and the radical emissions for two levels of boiler power (130 and $150 \mathrm{~kW})$, as a function of the excess air. The optimal operation condition is clearly given by critical excess air when $\mathrm{CO}$ emissions increase abruptly and the boiler efficiency began to decrease at low levels of air excess, as show in figure 4 (a, b, c and d).

From the point of view of the pollutant emissions, the trends of NOx curves (figure 4, c and d) are very similar to the radical emissions (e and $\mathrm{f}$ ). The intensity emissions of both radicals, $\mathrm{CH}^{*}$ and $\mathrm{C}_{2}{ }^{*}$, show a similar behaviour. The maximal levels are achieved at excess air values higher than the critical one defined by increased CO. However, these maximal levels shows a slight diphase for $\mathrm{CH}^{*}$ and $\mathrm{C}_{2}$ * radicals, according to the observations of Gaydon and others $[8,3]$.

In figure $4\left(\mathrm{~g}\right.$ and $\mathrm{h}$ ) one can observe the trends of the $\mathrm{C}_{2} * / \mathrm{CH}^{*}$ intensity ratio, which increases while excess air decreases to a level near to the critical point of incomplete combustion, i.e. when $\mathrm{CO}$ increases abruptly.

\section{Conclusions}

The experimental result shows that the $\mathrm{C}_{2} * / \mathrm{CH}^{*}$ intensity ratio is a good indicator of the combustion state, because it permits prediction of the point of optimal air excess condition in order to obtain the maximal efficiency of the equipment, assuring a low level of pollutants ( $\mathrm{CO}$ and $\mathrm{NOx}$ ). This fact has been verified for two power conditions of a gas boiler. From this result it is possible to perform an optimal strategy of combustion control.

The fast response, non-intrusive character, and low cost yield to the developed optical sensor is an important potential to be used in advanced control strategies for the on-line optimization of the combustion process.

\section{References}

[1] Michel J. B., Champinot C., and Dugue J. State of the art on emerging combustion control sensors, 6th Int'l Conf. on Tech. and Combustion for a Clean Environment, Oporto, 2001.

[2] Zizak, Giorgio. Flame Emission Spectroscopy: Fundamentals and Applications, CNR-TeMP, Instituto per la Tecnologia dei Materiali e dei Processi Energitici Via Cozzi 53, 20125 Milano, Italy, 2000.

[3] Farias, O. Towards the Development of an Optimal Combustion Control in Fuel-Oil Boilers from the Flame Emission Spectrum, Thèse de Doctorat, Faculte des Sciences Appliquees, Universite de Liege, Belgique, 1997.

[4] Ikeda, Y., Kojima J., and Nakajima, T. Fast Response Local Equivalence Ratio Measurement in Premixed Turbulent Flame. Department of Mechanical Engineering, Kobe University, Japan. 
[5] Docquier N., Candel, S.: "Combustion control and sensors: a review", Laboratoire EM2C, Ecole Centrale Paris, CNRS UPR 288, Grande Voie des Vignes, F-92295 Châtenay-alabry Cedex, France, 2001

[6] Webber, M., Wang, J., Sanders, S., Baer, D. and Handson, R. In situ combustion measurements of $\mathrm{CO}, \mathrm{CO}_{2}, \mathrm{H}_{2} \mathrm{O}$ and temperature using Diode Laser Absorption Sensors, High Temperature Gasdynamics Laboratory, Department of Mechanical Engineering, Standford University, Standford, CA 94305-3032, USA.

[7] Romero, C., Li, X., Keyvan, S. and Rossow, R. Spectrometer-based combustion monitoring for flame stoichiometry and temperature control, Energy Research Center, Lehigh University, Bethlehem and Center for artificial Intelligence in Engineering and Education, University of Missouri, Columbia, USA, 2004.

[8] Gaydon A.G. and Wolfhard H.G., Flames: their structure, radiation and temperature, Chapman and Hall Ltd, 1970.

[9] Bar-ziv, E. Thermal Radiation and Optical Pyrometry, Department of Mechanical Engineering Ben-Gurion University, Beer-Sheva, Israel, 2003.

[10] Farias, O., Ngenndakumana P. Diagnóstico de la combustión, a partir del espectro de llamas luminosas, Revista de Ingeniería, Universidad de Concepción, Chile. Año 10, Edición N¹, Noviembre 1998.

[11] Ngendakumana P., Zuo B. and Winandy E., A spectroscopic study of flames for a pollutant formation regulation in a real oil boiler, 2nd International Conference on Combustion Technologies for a Clean Environment, Lisbon, 1993.

[12] Pearse R. W, Gaydon A.G The identification of Molecular Spectra, Chapman and Hall, London, 1965

[13] Adams W.H. Heat transmission, Mc Graw-Hill Publishing Company Ltd, London, 1954.

[14] Khesin, M. Demonstration tests of new burner diagnostic system on a 650 MW coal-fired utility boiler, American Power Conference, 59th Annual meeting, 1997.

[15] Khesin, M. Demonstration of new frequency-based flame monitoring system, Proc. 59th Ann. Mtg. of the American Power Conf., Vol: 58-II, pp. 1010-1013, 1997

[16] Michel, J., Chetelat, O. Flame Signature as a Low-Cost Flame Control Method, 5th Int'l Conf. on Tech. and Combustion for a Clean Environment, pp. 1251-1253, 1999

[17] Ballester, R., Sanz, A. Advanced monitoring and control of burners using flame sensors, Fluid Mechanics Group / LITEC, University of Zaragoza, Spain, 2006.

[18] Ballester, R., Sanz, A. Identification of combustion conditions using flame sensors, 2005 AFRC Intl. Symposium on Dynamics and Control of Industrial Combustion Processes, Georgia Institute of Technology

[19] Martins C., Carvalho J., Ferreira M.: $\mathrm{CH}$ and $\mathrm{C}_{2}$ radicals characterization in natural gas turbulent diffusion flames, Journal of the Brazilian Society of 
Mechanical Sciences and Engineering Print ISSN 1678-5878 J. Braz. Soc. Mech. Sci. \& Eng. vol.27 no.2 Rio de Janeiro Apr./June 2005

[20] Kauranen P., Aandersson-engels S. Spatial mapping of flame radical emission using a spectroscopy multi-color imaging system, Department of Physics, Lund Institute of Technology, Lund, Sweden, 1991

[21] Sbárbaro D., Farias O. Real time monitoring and characterization of flames by principal-components analysis, Department of Electrical and Mechanical Engineering University of Concepcion, 2002.

[22] Morrel M., Seitzman J. Interpretation of optical emissions for sensors in liquid fueled combustors, AIAA-2001-0787 at the 39th AIAA Aerospace Sciences Meeting, Reno, NV, January 8-11, 2001 